\title{
Findings About Events or Interventions Sequence Number
}

National Cancer Institute

\section{Source}

National Cancer Institute. Findings About Events or Interventions Sequence Number. NCI

Thesaurus. Code C87889.

A number that identifies the ordering relations (in time, space, etc.) in a set of findings. 